\title{
Prevalence and Knowledge of Brucellosis in Dairy Cattle in Makuyu Division, Murang'a County, Kenya
}

\author{
Mwangi Rachel Mbaire, B.Ed (Sc.)
}

\begin{abstract}
Brucellosis is a cosmopolitan zoonotic disease that affects man, domestic animals and wildlife. The bacteria Brucella abortus is the principle cause of brucellosis in cattle. The incidence of the disease in humans, and which directly relates to that in other animals, is highly dependent on animal husbandry practices, the interaction between humans and animals, living standards, hygiene, food customs, and animal and human population density. Makuyu Division where the study was undertaken experiences hot and dry climate, the area has no permanent rivers and domestic water is obtained from boreholes. Most families live in congested homes and are provided with relieve food by the Government. The standard of hygiene is very low and most of the people are poor. In August 2009 six cases of retained placenta disease were reported to Makuyu veterinary Department among other diseases. Most people are readily exposed to infected animals or indirectly to milk, water and environment contaminated by brucellosis. It is for these reasons that the study was undertaken with the aim to determine prevalence of Brucella abortus in dairy cattle and assess knowledge of the disease among the dairy farmers. The study involved random sampling of dairy cattle in the division and a representative sample of two hundred and eight milk and blood samples were collected. The samples were screened at the Central Veterinary Laboratories, Kabete. Immunological tests were used to test presence of Brucella abortus antibodies. A questionnaire was used to assess knowledge of brucellosis among the dairy farmers and determine utilization and accessibility to veterinary services. Data analysis involved descriptive statistics to obtain prevalence rate. The percentage prevalence of brucellosis in dairy cattle as determined by both MRT and RBPT were 7.7\% and $1.9 \%$ respectively. Knowledge of brucellosis was significantly related to the age and level of education of the farmers. The young and educated farmers were more knowledgeable on brucellosis than those who were old and not educated. The old and not educated were the majority and they had no idea on what causes brucellosis in cattle. The Ministries of Health and Agriculture, Livestock and Fisheries will use the results in targeting education and prevention programs to address the disease. Farmers will be educated on methods of controlling brucellosis to reduce prevalence, use of artificial insemination to reduce venereal transmission of brucellosis during mating, herd health campaign with frequent screening for brucellosis to identify infected animals so that they can be slaughtered to eradicate the disease and food and occupational hygiene to prevent transmission of brucellosis to human beings.
\end{abstract}

Keywords: Brucellosis, Brucella species, Milk Ring Test

\section{Chapter One: Introduction}

\subsection{Background Information}

Brucellosis is often called "undulant fever" or "Bang's disease," (Cloeckaert et al., 2003). The importance of this disease in humans dates back to 1887 when David Bruce first isolated the causative agent from livers of British soldiers dying in Malta (Young, 2009). In human the clinical signs are mild fever, enlarged lymph nodes, and weight loss. In cattle the clinical signs are abortion, arthritic joints and retained afterbirth (Dricot et al., 2004). Four varieties of the genus Brucella cause brucellosis in human. Brucella abortus invades cattle; Brucella canis, dogs; Brucella melitensis, goats and Brucella suis, pigs (Gumber et al., 2004). In human Brucellae enter the body mainly through ingestion of unpasteurized milk (Hasanjani, 2006). In cattle, transmission occurs by ingestion of organisms in aborted fetuses, foetal membranes, vaginal discharges, contaminated feeds and water (Hong et al., 2000).

Brucellosis is typically a chronic infection of domestic animals involving the mammary glands and the uterus, thereby contaminating milk and causing abortions in the affected animals (Jennings et al., 2007). The most important control measures against brucellosis are pasteurization of dairy products and inspection of domestic animals for evidence of the disease. An attenuated vaccine effectively controls the disease in domestic animals (Seismenis, 1998). In Kenya, prevalence of brucellosis is high in Narok and other pastoral areas where it is endemic. Many cases have been reported in the various annual reports of the ministry of agriculture and other literature (Muriuki et al., 1994). Serological tests for 10 years (1978-1987) at Veterinary Laboratories in Kabete, revealed that $17.08 \%$ cattle $(\mathrm{N}=16,273) 4 \%$ goats $(\mathrm{N}=2,851)$ and $7 \%$ sheep $(\mathrm{N}=1,374)$ were infected (Kagunya and Waiyaki, 1978).

In August 2009, six cases of retained placenta disease were reported to Makuyu veterinary Department among other diseases (DVO, 2009). The Makuyu Health Centre officers reportedly refer about $5 \%$ of patients every two months to bigger hospitals on suspicion that they suffer from brucellosis (Dr Kamau-personal communication). It is for this reason that this study was undertaken with the aim of determining prevalence of brucellosis by establishing the reactor rate of randomly sampled dairy cattle in Makuyu Division. It is important to carry out the study so that the Ministries of Public Health and Livestock can use the results in targeting education and prevention programs to address the disease. The farmers can also be educated on how to handle infected animals to prevent transmission of brucellosis to human and the disease control measures in general. 


\section{International Journal of Science and Research (IJSR) \\ ISSN (Online): 2319-7064}

Index Copernicus Value (2013): 6.14 | Impact Factor (2014): 5.611

\subsection{General Objective}

To determine prevalence and knowledge level of brucellosis in dairy cattle in Makuyu Division Murang'a County Kenya.

\subsubsection{Specific objectives}

i) To determine prevalence of Brucella abortus antibodies in milk and serum from dairy cattle in Makuyu Division.

ii) To assess the knowledge level of brucellosis among the dairy farmers in Makuyu Division. iii) To evaluate the accessibility of veterinary services to dairy farmers in Makuyu Division.

\section{Chapter Two: Literature Review}

The genus Brucella consists of species of small non-motile, non-spore forming, gram-negative aerobic coccobacilli (Dricot et al., 2004). There are four types of Brucella species and each has a prediction for a specific host but will also infect a wide range of other animals and humans. Brucella abortus is for cattle, Brucella melitensis for goats and to a lesser extent sheep, Brucella ovis causes epididymitis in rams and Brucella canis for dogs (Harze, 2002). All the pathogenic members of the genus target cells of the host's reticulo-endothelial system, into which they lounge (Cloeckaert et al., 2003). These organisms are destroyed by exposure to high temperature at $60^{\circ} \mathrm{C}$ for 10 minutes, exposure to phenol for at least 15 minutes or exposure to low temperatures such as at $0^{\circ} \mathrm{c}$ for a month (Ettunge, 1995). Their optimum temperature for growth is $37^{\circ} \mathrm{C}$ and the most suitable $\mathrm{pH}$ is 6.6-7.4 (Capasso, 2002). Some species like Brucella abortus are metabolisers of mesoerythritol abundant in pregnant uteri of some animals and improves in-vivo growth (Jubb et al., 1993). In vitro growth is improved by addition of serum, blood or tissue extract. Serum dextrose broth and agar are ideal (Mclean, 1992). Their cell wall is made up of lipopolysaccharideprotein which maintains cell structure and provides protection from host antibodies.

Man acquires brucellosis mainly by eating or drinking contaminated milk products from infected cows, sheep and goats (Gall and Nielsen, 2004). If the milk is not pasteurized, these bacteria can be transmitted to persons who drink the milk or eat cheese made from it. Brucella organisms can enter into the body through skin wounds which is a problem mainly for persons working in slaughter houses or meat packaging plants or for veterinarians. Handling new born animals or foetal membranes is a common direct method of transmission. (Makitat et al., 2008). In animals transmission of Brucella is very likely to occur via the oral route because animals tend to lick aborted foetuses and genital discharge of the aborting animal. It is also likely to occur in utero or when calves born to healthy dams are fed on colostrum or milk from infected dams (Abbas and Aldeewan, 2009). Animals infected by Brucella organisms accord themselves protection by production of humoral antibodies: IgG and IgM among others, and cell mediated immunity (CMI), or both. Vaccination also offers protection by production of humoral antibodies and probably by stimulating CMI (Stephens et al., 1995). The methods commonly used in diagnosis of brucellosis include Rose
Bengal Plate Test (RBPT), Milk Ring Test (MRT), Serum Agglutination Test (SAT) and Complement Fixation Test (CFT). Other available tests are Card Test, Rivanol Test, Coombs Antiglobulin Test, 2-Mercapto-ethanol (ME) and Enzyme linked Immunoabsorbent Assay (ELISA) (Faye et al., 2005).

Human disease is best controlled by effective control of disease in animals (Shirima, 2005). The most important control measures against human brucellosis are pasteurization of dairy products and inspection of domestic animals for evidence of the disease. The use of goggles or face shield and rubber gloves helps protect veterinarians, butchers and slaughter house workers. Treatment for brucellosis is by use of combinations of drugs which are tetracycline and streptomycin, doxycycline and rifampin (Dricot et al., 2004). The most extensively used vaccines in control of animal brucellosis are Brucella abortus strain 19 and Brucella melitensis rev-1 (Pappal et al., 2004).Test and slaughter is also effective and quick but expensive and sometimes impractical when the prevalence is high. It has however been noted that where all animals in an infected herd have been slaughtered, brucellosis does not recur.

\section{Chapter Three: Materials and Methods}

Makuyu Division is divided into 12 locations. Thika-Sagana highway forms the boundary to the East, Kenol-Murang'a highway to the West and River Thara to the North. The Murang'a-Ruiru railway line passes through the division on the West. The division is served by several dry weather roads. Small scale farmers form a greater percentage of population and livestock farming is mainly on zero grazing units.

According to August 2009 census records at Makuyu livestock centre, there were 435 dairy cattle in Makuyu Division. A representative sample size of number of dairy cattle was determined using the formula deduced by Yamane (1967).

$$
n=\frac{N}{1+N(e)^{2}}
$$

Where; $\mathrm{n}=$ Sample size, $\mathrm{N}=$ Population size, $\mathrm{e}=$ Level of precision at $95 \%$ confidence interval.

$$
\text { Samplesize }=\frac{435}{1+435(0.5)^{2}}=208.38
$$

This study involved any lactating dairy cattle regardless of the breed and excluded non-lactating dairy cattle. This cross sectional study involved multi-stage sampling of dairy cattle in Makuyu Division. The twelve locations in the division were numbered and using systematic sampling, every third location was selected hence first, fourth, seventh and eleventh locations. Each location was divided into thirteen clusters of homesteads using cluster random sampling. From each cluster of homesteads four lactating dairy cows were selected using simple random sampling. Each lactating dairy cattle in a cluster was assigned a number, and four numbers were picked from the total randomly. Therefore a total of 208 dairy cows were used in this study. The owner of the cow was also interviewed using a questionnaire. The types of questionnaires were structured non distinguished 


\section{International Journal of Science and Research (IJSR) \\ ISSN (Online): 2319-7064}

Index Copernicus Value (2013): 6.14 | Impact Factor (2014): 5.611

questionnaire in which questions were listed in a prearranged order and the respondent told about the purpose of collecting information and non-structured non distinguished questionnaire in which questions were not structured, researcher was free to ask questions in any sequence and respondents were told about purpose of collecting information. The types of questions included closed ended questions in which the respondent selected answers from a fixed list of replies and chose any one of the multiple options given and open ended questions in which the respondent gave his or her opinion. The head of the homestead or person taking care of the cattle was interviewed and about $90 \%$ responded to the questionnaires.

Serum was screened using Rose Bengal Plate Test (RBPT) while milk was tested using Milk Ring Test (MRT) in Central Veterinary Laboratories at Kabete. Descriptive statistics was used to analyze the data collected using questionnaires to show whether veterinary services are accessible to the dairy farmers. Social data to establish relationship between levels of education and knowledge were analysed using chi-square. Level of significance was $P<0.05$. Prevalence of brucellosis was analysed by use of central tendencies particularly the percentages. Percentage prevalence of brucellosis in Makuyu Division was calculated based on the number of positive animals detected using milk and serum samples.

\section{Chapter Four: Results}

\subsection{Demography of the farmers}

This study established that most of dairy farmers in Makuyu Division are above 40 years of age (76.4\%). Between 31 and 40 years they were $13.5 \%$ while the rest were below thirty years. Over half of the respondents were females (56.7\%). Although most of the respondents were literate over a fifth of them reported not to have had any formal education (Figure 4.1). About $60 \%$ had either attained primary or secondary school level of education.

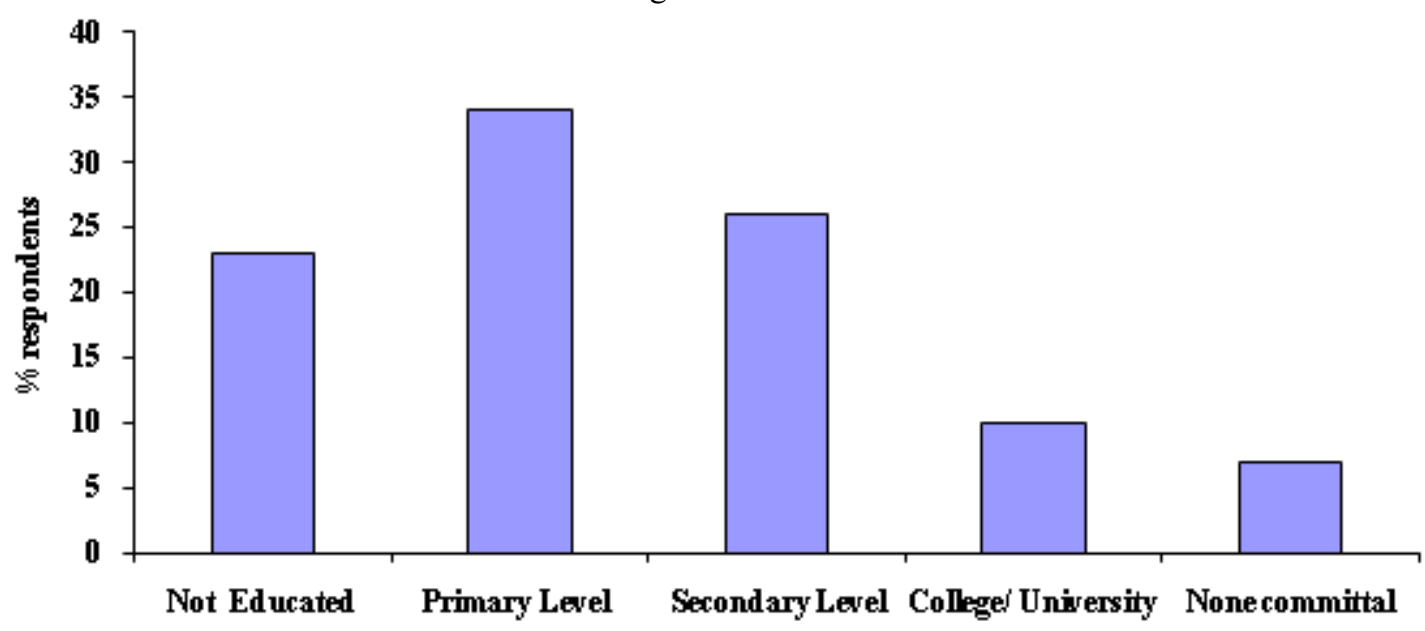

Figure 4.1: Education levels of the respondents from Makuyu Division, Murang'a County n=208

\subsection{Number of animals, breeds and farming practices}

Since most farmers in Makuyu Division are small scale they keep less than ten animals. Friesian, Ayrshire and their classes with indigenous breeds are most common in Makuyu region. Majority (43.3\%) of the farmers owned mixed breed, sixty two (29.8\%) Ayrshire only while fifty six (26.9\%) owned Friesian breed of cattle. Dairy farming is a labour intensive activity which generates employment, at least casual labour. In this area, one hundred and fifty three $(73.6 \%)$ of the respondents practice zero grazing, forty one (19.7\%) graze in an open field while fourteen $(6.7 \%)$ of the farmers have paddocks in their farms where the animals are grazed.

\subsection{Knowledge of brucellosis among dairy farmers}

Majority of farmers (174) reported to have heard about brucellosis (Figure 4.2). These farmers suggested the following as the main symptoms of a cattle suffering from brucellosis; reduced production of milk, swollen mammary glands, abortion, malaria like symptoms and blood stains in faecal matter. Abortion is the main symptom of brucellosis in cattle. However, most of them $(83.7 \%)$ had no idea on what causes this disease but a few of them (6.7\%) thought brucellosis is caused by bacteria or virus while six $(2.9 \%)$ of the respondents thought it is caused by fungi Brucellosis is caused by bacteria.

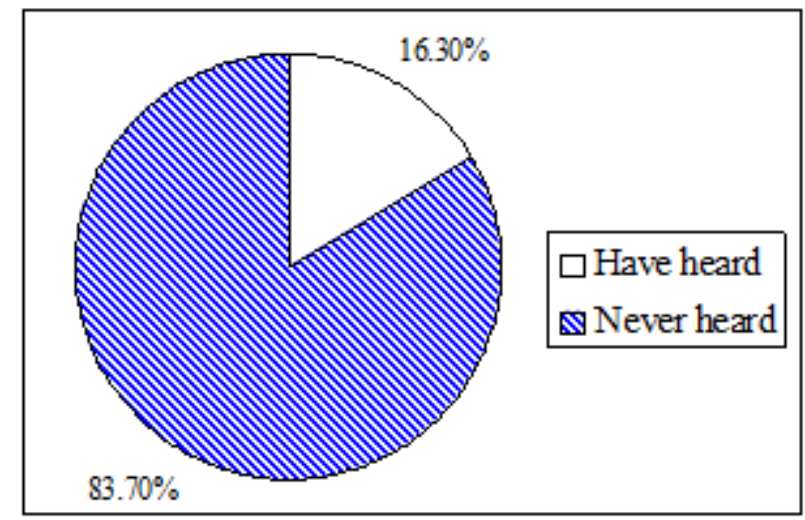

Figure 4.2: Respondent farmer's knowledge status on existence of brucellosis in Makuyu Division, Murang'a County $n=208$

There was a significant relationship between level of education and knowledge on what causes brucellosis $\left(\chi^{2}=\right.$ 82.542; $P<0.05)$. Farmers having secondary and college 


\section{International Journal of Science and Research (IJSR) \\ ISSN (Online): 2319-7064 \\ Index Copernicus Value (2013): 6.14 | Impact Factor (2014): 5.611}

education are more knowledgeable about the causes of this disease (Figure 4.3). Most of the farmers (70.2\%) were aware that this disease can infect human beings and hence they are cautious when handling suspected animals and their products. The rest of the farmers also practice good hygiene in handling animals and their products such as boiling milk. Majority of the farmers $(67.3 \%)$ said they have either been infected or seen a person suffering from brucellosis. The farmers strongly believe that this disease can be spread to human beings through raw milk as indicated by $63.5 \%$ of the respondents. According to the farmers, the known symptoms of brucellosis on human beings were; joint pain and body weakness, fever and headache, vomiting and backache.

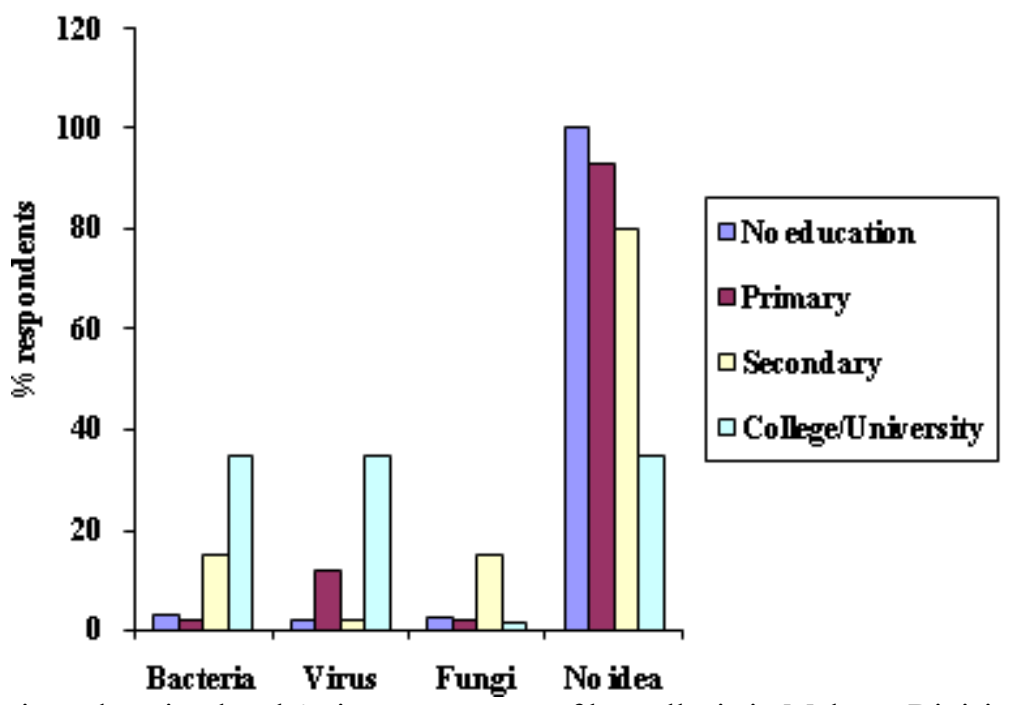

Figure 4.3: Farmers of varying education levels' views on causes of brucellosis in Makuyu Division, Muranga County n=208

Knowledge of brucellosis was also significantly related to the age of the respondents $\left(\chi^{2}=35.800 ; P<0.05\right)$. Interestingly, younger farmers had heard of the disease called brucellosis more than the older respondents. All $(100 \%)$ of the respondents in the age bracket of $26-30$ years had heard of the disease while $75 \%$ of those in $31-40$ years and $83 \%$ of those above 40 years had not heard of brucellosis.

\subsection{Control of brucellosis}

The rate of abortion in cattle in the study area is relatively high as sixty three percent of the famers reported that their cattle abort. They were however not aware of what exactly caused the abortion. When this occurred, about one hundred and thirty nine $(66.8 \%)$ of the farmers buried the carcasses while twenty seven $(13.0 \%)$ gave the carcasses to dogs. Other hygiene practices include washing hand and udder before milking, using hot water when washing, using clean milking cans and observing good hygiene of the person milking. Most of the farmers $(73.1 \%)$ sell part of their raw milk to their neighbours, neighbouring shopping centres or to dairy firms. However, any milk meant for domestic consumption is boiled in two hundred and one (96.6\%) of the households. Forty (19.2\%) of the farmers indicated that they ferment some milk for domestic consumption.

\subsection{Veterinary services}

Ninety one $(43.8 \%)$ of the respondents knew there are veterinary doctors going around the Division. However, in some parts, the veterinary doctors only provide the services when requested by the farmers. Most of the farmers $(86.5 \%)$ reported to have had their animals vaccinated at least once in a year. Seven $(3.4 \%)$ of the farmers have their animals vaccinated once in a month while another seven (3.4\%) get their animals vaccinated when sick. These farmers did not indicate the disease against which their animals were vaccinated. Fourteen $(6.8 \%)$ of the farmers however, failed to indicate the frequency of the vaccination indicating that they may not be vaccinating their animals. When the farmers call a veterinary doctor to attend to their animals, one hundred and eighty seven $(89.9 \%)$ of the farmers realized the doctors do tell them the disease and drug used to treat the animals. In many cases (63.9\%), the animals get healed after treatment (Figure 4.4). If the animal is suffering from brucellosis, the farmers suggested the following options; treat the animal, vaccinate all the animals, use artificial insemination to avoid transmission, educate farmers through extension services and slaughter the sick animal.

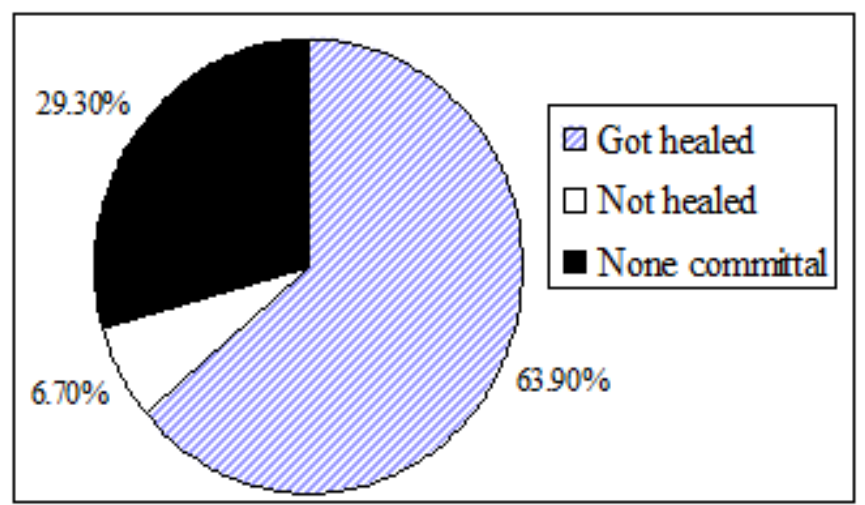

Figure 4.4: Respondents reports on outcome of treatment in Makuyu Division, Murang'a County n=208

\subsection{Prevalence of brucellosis in Makuyu Division}

The two methods used to test brucellosis gave different results. The Milk Ring Test detected 16 cases and RBPT 4 out of the 208 animals diagnosed. This is a prevalence of 


\section{International Journal of Science and Research (IJSR) \\ ISSN (Online): 2319-7064}

Index Copernicus Value (2013): 6.14 | Impact Factor (2014): 5.611

$7.7 \%$ and $1.9 \%$ (Table 1 ). The rate of prevalence also varied with the breed of animal. Most of the animals that were infected were Fresians. Overall brucellosis was more prevalent in Fresian (13.27\%) than in Ayrshire (9.43\%).

Table 1: Prevalence of brucellosis as diagnosed in milk and blood samples

\begin{tabular}{|c|c|c|c|}
\hline Methods & $\begin{array}{c}\text { Fresian } \\
\text { positive }\end{array}$ & $\begin{array}{c}\text { Ayrshire } \\
\text { Positive }\end{array}$ & $\begin{array}{c}\text { Total } \\
\text { percentage }\end{array}$ \\
\hline Milk Ring Test & 10 & 6 & $7.7 \%$ \\
\hline Rose Bengal Plate Test & 4 & 0 & $1.9 \%$ \\
\hline
\end{tabular}

Percentage prevalence of the occurrence of brucellosis in Makuyu Division, Murang'a County -Kenya was therefore calculated based on the number of positive animals detected using milk and serum samples from 208 animals.

$\%$ prevalence $=\frac{\text { Positive samples }}{\text { Total number of animals }} \times 100$

Positive samples detected using milk and serum were sixteen (16) and four (4) respectively while the total numbers of animals sampled were two hundred and eight (208).

Percentage prevalence of brucellosis in Makuyu Division based on MRT and RBPT respectively was therefore $7.7 \%$ and $1.9 \%$.

\section{Chapter Five: Discussion}

Brucellosis is an infectious disease of non-human mammals that is contagious for man. The zoonotic disease mainly caused by Brucella abortus which infect cattle has severe hazards to human health (Hasanjani, 2006). In cattle the clinical signs are abortion, arthritic joints and retained after birth. It is transmitted by ingestion of Brucella in aborted foetuses, vaginal discharges, contaminated feeds and water and venereal transmission by infected bulls (Omer et al., 2000). In man transmission is mainly by ingestion of contaminated milk and milk products (Young, 2009). Clinical signs are mild fever, weakness, enlarged lymph nodes and weight loss. Application of serological diagnostic tests for brucellosis has been achieved in diverse areas using RBPT and MRT (Kagumba and Nandokha, 1978). These two tests and questionnaires were used to obtain information on Brucella abortus antibodies in dairy cattle and public knowledge of brucellosis among dairy farmers in Makuyu Division.

The young and educated farmers were more knowledgeable on brucellosis than those who were old and not educated. Some of the farmers reported that when their cows abort they give the carcasses to dogs which may also have lead to increased spread of the disease. This is related to Uganda where poor disposal systems for aborted materials because of poor community knowledge about the zoonotic implications of the disease and the collapse of the animal health service sector in the rural areas as a result of privatisation of veterinary services contributed to perpetuation of the disease (Makita et al., 2008). Veterinary services are available and accessible to the dairy farmers thus minimizing spread of the disease. Majority of the farmers indicated that they do not use artificial insemination. In Egypt use of artificial insemination is encouraged as opposed to bulls to reduce prevalence of brucellosis (McDermott, 2002).

The overall prevalence of brucellosis as determined by both MRT and RBPT were $7.7 \%$ and $1.9 \%$ respectively. The Brucella organisms localize mainly in the lymphatic tissue, especially the supra-mammary lymph nodes, from where they are excreted via the mammary gland (Eisencheck et al., 1995). The percentage prevalence of brucellosis in Makuyu Division based on milk samples was relatively high compared to others reported in some parts of the country. Kang'the et al. (2000) reported an overall prevalence of brucellosis at consumer-level and informal market level as $3.9 \%$ and $2.4 \%$ using MRT. Informally traded raw milk from dairy co-peratives and milk bars had the highest proportion of MRT positive samples and all these samples were from Narok District where extensively grazed pastoralist zebu herds predominate. The few cases recorded with RBPT may be due to the fact that people in this Division have small pieces of land and some of the farmers move their animals from one place to another searching for pastures. Using RBPT, Junaidu et al. (2008) reported prevalence of $5.1 \%$ among nomadic cattle herds and $4.4 \%$ in settled cattle in Adamawa state in Nigeria. Movement of pastoral Fulani herdsmen and interaction of cattle with those of other Fulani herdsmen is a major factor in spreading brucellosis in Nigeria.

The overall brucellosis was more prevalent in Fresian (13.27\%) than in Ayrshire (9.43\%) and also no antibodies were detected in the blood in Ayrshire type of breed. In Nigeria, Junaidu et al. (2008) reported the Sokoto Gudali breed to have the highest prevalence of brucellosis followed by Azuwarq, with Bunaji having the least. Genetic variation is an important factor in conferring resistance or tolerance of cattle breeds to a wide range of diseases. Significant genetic variability in resistance/susceptibility to brucellosis has been detected in cattle and is associated with a $3^{\prime}$ untranslated polymorphism in the slc1al gene (Samaha et al., 2008).

\section{Chapter Six: Conclusion And Recommendations}

\subsection{Conclusion}

i) Most of the dairy farmers are aware that brucellosis can infect human beings and hence practice good hygiene in handling suspect animals and their products.

ii) Knowledge of brucellosis among dairy farmers is related to their education level and age. The young who are more educated are aware of the symptoms of the disease while the old and not educated are not.

iii) Veterinary services are accessible to the farmers, sick cattle are treated and most are healed. Veterinary doctors also inform farmers of the disease the sick animals suffer which may reduce prevalence of brucellosis.

\subsection{Recommendations}

i) Public education on methods of controlling brucellosis to reduce prevalence of the disease in dairy cattle. 


\section{International Journal of Science and Research (IJSR) \\ ISSN (Online): 2319-7064}

Index Copernicus Value (2013): 6.14 | Impact Factor (2014): 5.611

ii) Heard health campaign with frequent screening for brucellosis to identify infected animals so that they can be slaughtered to eradicate the disease.

iii) Use of artificial insemination as opposed to bulls to control venereal transmission of brucellosis.

iv) Future research on prevalence of brucellosis in human beings, goats and dogs.

\section{References}

[1] Abbas, B. and Aldeewan, A. (2009). Occurrence and epidemiology of Brucella species in raw milk samples at Basrah province, Iraq. Bulgarian Journal of Veterinary Medicine 12: 136-142.

[2] Bruce, D. (1887). A contribution to historical understanding of brucellosis in Chile. American Medical Association 103: 665-677.

[3] Capasso, L. (2002). Bacteria in two Millennia-old cheese, and related epizoonoses in Roman population. Pan American Health Organization Science Publication 45 (2): 122-127.

[4] Cloeckaert, A., Grayon, M., Grepinet, U. and Boumedine, K. S. (2003). Classification of the Brucella strains isolated from marine mammals by unfrequented restriction sitePCR and development of specific PCR identification tests. Microbes Infection. 5: 593-602.

[5] Dricot, A., Rual, J. F., Lame, P. and Beltru, N. (2004). Generation of Brucella Melitenisis. Genome research 4: 2201-06.

[6] District Veterinary Office (DVO), Murang'a South, (2009). Annual report on diseases infecting cattle in Makuyu Division. $17^{\text {th }}$ August 2009.

[7] Eisencheck, F. C., Honle, J. J. and Hoffman, E.M. (1995). Serum sensitivity of filed isolates and laboratory strains of Brucella abortus isolates. Veterinary Research 56 (12): 1592-98.

[8] Ettunge, S. J. (1995). Text book of veterinary Internal Medicine WB Saunders Company. 654.

[9] Faye, B., Castel, V., Lesnoff, M., Rutabinda, D. and Dhaiwa, J. (2005). Turberculosis and brucellosis prevalence survey on dairy cattle in Mbarara milk basin (Uganda). Prevalence Veterinary Medicine 67: 267-281.

[10] Gall, D. and Nielsen, K. (2004). Serological diagnosis of brucellosis: A review of test performance and cost comparison. Veterinary Research 23: 989-1002.

[11] Gumber, S., Aradhana, N., Dhand, N. and Sondhu, K. (2004). Village level study of brucellosis in Punjab (India) by bulk milk analysis. Indian Journal of Animal Science 74: 843-844.

[12] Harze, N. D. (2002). Brucella virulence genome biology: The genome sequence of the facultative intracellular pathogen Brucella melitensis. Infection and Immunity 43: 786-790.

[13] Hasanjani, R. (2006). Efficacy of gentamicin plus doxycycline versus streptomycin plus doxycycline in the treatment of bruccellosis in human clinic infectious disease. Infection and Immunity 42 (8): 1075-1080.

[14] Hong, J., Elzer, p., Rowe, G. and Araya I. (2000). Epizoology of brucellosis and its relationship to the identification of Brucella organisms. American Journal Veterinary Research 25: 553-557.

[15] Jennings, G., Hajjeh, R., Grgis, F., Fadeel, M., Maksoud, M. and Wsfy, M. (2007). Brucellosis as a cause of a cute fibrile illness in Egypt. Transactions of the Loyal Society of Tropical Medicine and Hygiene 101: 707-713.
[16] Jubb, K. V., Kennedy, P. C. and Palmer, N. (1993). Disease of pregnant uterus, bones and joints. Pathology of domestic animals $3^{\text {rd }}$ ed. Academic Press London. 3: 396412.

[17] Junaidu, A., Oboegbulem, S. and Salihu, M. (2008). Seroprevalence of brucellosis in prison farm in Sokoto, Nigeria. Veterinary Medical Association 137: 256-261.

[18] Kagumba, M. and Nandokha, E. (1978). A survey of the prevalence of bovine brucellosis in East Africa. Veterinary Microbiology 90: 111-134.

[19] Kagunya, D. and Waiyaki, P. (1978). A serological survey of animal brucellosis in North Eastern Province of Kenya. Veterinary Research 2: 35-40.

[20] Kangethe, E. K., Arimi, S. M. and Omore, A. (2000). The prevalence of antibodies to Brucella abortus in marketed milk in Kenya and its public health implications, in proceedings of the $3^{\text {rd }}$ All African Conference on Animal Agriculture.

[21] Kang'ethe, E. K., Ekuttan, C. E. and Kiragu, M. W. (2007). Investigations into the prevalence of bovine brucellosis and the risk factors that predispose humans to infections among urban dairy and non-dairy farming households in Dagoretti. East Africa Medical Journal 77: 65-69.

[22] Makita, K., Fevre, E. and Waiswa, C. (2008). Human brucellosis in urban and peri- urban areas of Kampala, Uganda. Applied Environmental Microbiology 49: 309311.

[23] McDermott, J. J. and Arimi, S. M. (2002). Brucellosis in Sub-Saharan Africa: Epidemiology control and impact. Veterinary Microbiology 90: 1-4.

[24] Mclean, D. (1992). Neurobrucellosis: clinical and therapeutic features. Clinical Infectious Disease 15 (4): 582-590.

[25] Muriuki, S. M., Arimi, S. M. and Mcdermont,J. J. (1994). Brucellosis as a course of human illness in Narok District, Kenya. Proceedings of $7^{\text {th }}$ Symposium on veterinary epidemiology and economics, Nairobi, $15^{\text {th }}$ to $19^{\text {th }}$ August 1994 Kenya Veterinary 18: 537.

[26] Omer, M., Skjerve, E., Holstad, G., Woldehiwet, Z. and Macmillan, A. (2000). Prevalence of antibodies to Brucella species and individual risk factors of infection in traditional cattle, goats and sheep reared in livestock wildlife interface areas of Zambia. Epidemiology and Infection 125: 447-4

[27] Pappal, G., Papadimitriou, P., Akritidis, N., Christou, L. and Tslanos, E. V. (2004). The new grobal map of human brucellosis. Lancet Infectious Diseases 6: 91-99.

[28] Samaha, H., Mohamed, T., Khoudair, R., Ashour, H. (2008). Sero-diagnosis of brucellosis in cattle and humans in Egypt. Veterinary Microbiolgy 78: 56-64.

[29] Shirima, G. M. (2005). The epidemiology of brucellosis in animals and humans in Arusha and Manyara regions of Tanzania Phd Thesis University of Glasgow.

[30] Stephens, M. G., Olsen, S. C. and Pugh, G. W. (1995). Comparison of immune response to brucellosis in mice vaccinate with s19 or RB-51. Iimmunity and Immunopathology 63 (1): 264-270.

[31] Yamane, T. (1967). Highly sensitive spetrophotometric kinetic determination. Economy and environmental program 171: 325-332.

[32] Young, E. J. (2009). Brucella species: Principles and practice of infectious disease. Churchil livingstone 226. 